\title{
Estimativa da transpiração em cafeeiros utilizando-se sensores de dissipação térmica
}

\author{
Jussálvia da S. Pimentel ${ }^{1}$; Tonny J. A. Silva ${ }^{2}$; João C. F. Borges Júnior ${ }^{2}$; Marcos V. Folegatti ${ }^{3}$ \& Abelardo A. A. Montenegro ${ }^{1}$
}

\begin{abstract}
RESUMO
Alguns métodos são capazes de determinar diretamente a quantidade de água consumida por uma planta, entre eles o "método de dissipação de calor" ou método de Granier. Neste trabalho se propôs, como objetivo, construir e calibrar sensores de dissipação térmica, avaliar a transpiração em função da posição de inserção do sensor na planta (Norte, Sul, Leste ou Oeste) e comparar os resultados com os elementos meteorológicos e a evapotranspiração de referência. Em 24 cafeeiros se instalaram sensores de dissipação térmica, adaptados de Granier (1985), em que o conjunto termopar e resistência foi inserido na agulha. Obteve-se a densidade de fluxo de seiva a partir da variação da diferença de temperatura entre as sondas e se acompanhou a transpiração, em função da transição entre os períodos diurno e noturno. O experimento foi avaliado em 3 períodos: antecedente à floração, na floração e no início da frutificação. Não houve diferença significativamente entre os ângulos de inserção para o fluxo de seiva. Quanto aos elementos meteorológicos, a radiação e a umidade relativa foram os fatores mais determinantes da transpiração obtendo-se, por análises de regressão coeficientes $R^{2}$ entre 0,84 e 0,80 .
\end{abstract}

Palavra-chave: coffea arabica, fluxo de seiva, irrigação, evapotranspiração

\section{Estimation of transpiration in coffee crop using heat dissipation sensors}

\begin{abstract}
Some methods are capable of directly determining the amount of water consumed by a plant, among them, the "heat dissipation method" or Granier method. This study aimed to: build and calibrate sensors of thermal dissipation; to evaluate the transpiration as a function of the position of insertion of the sensor in the plant (North, South, East or West) and to compare the results with the meteorological elements and the evapotranspiration of reference. In 24 coffee plants, thermal dissipation sensors adapted from Granier (1985) were installed, where the whole thermocouple and resistance were inserted into the needle. Density of the sap flow was obtained from the variation of the difference in temperature between the probes and accompanied transpiration according to the transition between day and night periods. The experiment was evaluated during 3 periods: before flowering, during the flowering and at the beginning of fruiting. There was no significant difference between the angles of insertion to the sap flow. Regarding the meteorological elements, radiation and relative humidity were the most determinant factors in transpiration, obtained by analysis of regressions with, $\mathrm{R}^{2}$ coefficients between 0.84 and 0.80 .
\end{abstract}

Key words: Coffea arabica, sap flow, irrigation, evapotranspiration

${ }^{1}$ DTR/UFRPE, Rua Dom Manoel de Medeiros s/n, Dois Irmãos, CEP 52171-900, Recife, PE. Fone: (81) 3320-6276. E-mail: jussalvia@yahoo.com.br; abelardo.montenegro@pq.cnpq.br

2 UAG/UFRPE, Av. Bom Pastor s/n, Boa Vista, CEP 55296-901, Garanhuns, PE. Fone: (87) 3761-0882. E-mail: tonny.silva@pq.cnpq.br

3 USP/ESALQ. Av. Pádua Dias 11, CEP 13418-900, Piracicaba, SP. Fone: (19) 3429-4380. E-mail: mvfolega@carpa.ciagri.usp.br 


\section{INTRODUÇÃO}

A cafeicultura brasileira passou por expansão intensa nas últimas décadas, incluindo-se a obtenção de bebidas com qualidade superior e maior rendimento econômico, o que levou a produção a se tornar cada vez mais dependente da complementação hídrica.

Com isto se concluiu que a irrigação é fator decisivo para se obter alta produtividade e qualidade dos grãos, obrigando os produtores a adotarem esta prática para garantir sua competitividade; entretanto, para que a aplicação de água seja eficiente é fundamental o conhecimento adequado da demanda hídrica da cultura que, por sua vez, é regulada por características intrínsecas da planta, do solo e do clima da região.

Quantificar o consumo de água de forma mais precisa significa melhorar as metodologias existentes, buscando-se novas técnicas que permitam avaliações mais rápidas, simples e precisas, razão pela qual se tem sido desenvolvido e testado numerosos métodos capazes de determinar diretamente a quantidade de água consumida por uma planta lenhosa de tamanho relativamente grande.

A estimativa da transpiração de espécies arbóreas em coberturas vegetais no campo tem sido feita preferencialmente nos últimos 15 anos pelo uso de métodos de fornecimento de calor ao caule, por uma das seguintes três técnicas: "pulso de calor” (Marshall, 1958), "balanço de calor” (Sakuratani, 1981) e "sonda de dissipação térmica” (Granier, 1985). Dessas técnicas, a de balanço de calor foi usada em cafeeiros (Gutiérrez \& Meinzer, 1994; Marin, 2003; Righi, 2004), mas os dois últimos autores relatam um problema nessa espécie, porque o uso de uma pasta siliconada para melhorar o contato sensorcaule causou posteriormente morte das plantas.

O método de Granier (sonda de dissipação térmica) consiste em fornecimento de calor, por meio de uma fonte regulável de energia elétrica e de potência constante no interior do caule, pelo uso de uma sonda e relaciona o transporte convectivo deste calor com o fluxo de seiva. Para isto são necessárias duas sondas com junção de termopar de cobre e constantan, verificando a diferença de temperatura do caule no ponto do aquecimento e outro abaixo, e assim obter uma temperatura diferencial, sendo esta dependente da velocidade de seiva (Granier, 1985; 1987). De acordo com DelgadoRojas (2003), no período de um dia, a máxima diferença de temperatura entre os dois pontos de medida significa que o fluxo de seiva é mínimo ou nulo, enquanto que a mínima diferença significa uma taxa máxima de fluxo de seiva através dessa área de transporte.

O “método de dissipação de calor” vem recebendo atenção nos últimos tempos em virtude de utilizar princípios físicos relativamente simples e poder ser aplicado diretamente no campo sem alterar as condições fisiológicas e micrometeorológicas da planta; desta forma e se levando em consideração a carência de informações sobre as relações hídricas em cafezais objetivou-se, com este trabalho, construir e calibrar sensores de dissipação térmica; monitorar o fluxo de seiva em 24 plantas adultas de Coffea arabica; avaliar o fluxo de seiva em função da posição de inserção do sensor na planta (sensores direcionados para Norte, Sul, Leste ou Oeste) e comparar os resultados com os elementos meteorológicos, como radiação solar, umidade relativa e ainda estimar a evapotranspiração por meio da equação de Penman-Monteith.

\section{MATERIAL E MÉTODOS}

\section{Caracterização da área experimental}

O trabalho foi desenvolvido no Planalto de Garanhuns, na mesorregião do Agreste Pernambucano, com altitude média de $980 \mathrm{~m}$. O clima é mesotérmico, com temperatura média anual de $20^{\circ} \mathrm{C}$ e precipitação pluviométrica de 1333,1 mm (Mota \& Agendes, 1986).

O experimento foi instalado na Fazenda São Luís, em plantas de café (Coffea arabica L.) da variedade Catuaí Vermelho com 4 anos de plantio, no município de Garanhuns (8 53’ 25” S; 36²9’34” W; 822,76 m). A área total plantada é de 7,5 ha, sendo a área experimental composta de 24 plantas, ocupando aproximadamente $130 \mathrm{~m}^{2}$.

O espaçamento de plantio adotado na fazenda é de 3,0 x 0,8 m; toda a área era irrigada por sistema localizado composto de gotejadores espaçados $0,8 \mathrm{~m}$ e vazão de $4 \mathrm{~L} \mathrm{~h}^{-1}$. No cafezal, a seleção das plantas foi feita de modo que elas fossem representativas da área e com troncos únicos (não bifurcados) para instalação dos sensores. As leituras foram iniciadas em setembro de 2007, estendendo-se até janeiro de 2008 .

Os elementos meteorológicos temperatura do ar, umidade relativa, velocidade e direção do vento e radiação incidente (radiação global) foram registrados em estação meteorológica automática do Sistema INMET (Registro A-322) instalada na Unidade Acadêmica de Garanhuns/UFRPE a aproximadamente $4 \mathrm{~km}$ da área experimental.

No centro da área experimental se instalaram um piranômetro, para determinação da radiação incidente, e dois psicrômetros de termopares, para medidas de temperatura do ar e umidade relativa. Na área experimental os dados coletados foram registrados automaticamente, através de um sistema de aquisição e armazenamento de dados (datalogger) da Campbell Scientific, modelo CR23X, com amostragem de leituras a cada $30 \mathrm{~s}$ e médias armazenadas a cada $15 \mathrm{~min}$.

\section{Descrição das medidas realizadas}

Para estimativa da área foliar se retiraram os ramos de 3 plantas representativas na mesma área do estudo, separaramse as folhas em terços inferior, médio e superior, as massas frescas de cada porção (terço) foram determinadas e retirada uma subamostra de $20 \%$ à base de peso, para efetuar as medições do comprimento das folhas; a área foliar foi determinada segundo a Eq. 1, proposta por Viudes et al. (2004):

$$
\text { Af }=0,224 * C^{2,1173} \quad R^{2}=0,96
$$

onde C é o comprimento medido em cm e Af é a área foliar dada em $\mathrm{cm}^{2}$.

Estabelecidas as proporções da área foliar total de cada terço, adotou-se o número de folhas do terço médio como representativo para se determinar a área foliar total das 24 
plantas do experimento, por método não destrutivo, ou seja, contando-se o número de folhas do terço médio (considerando-se um comprimento médio de folha de $8,3 \mathrm{~cm}$ ) e se realizando o somatório dos resultados da Eq. 1.

Obteve-se a área total de cada planta a partir da área estimada no terço médio atribuindo-se sua relação (23\%) à planta toda. Estimou-se o diâmetro do tronco por meio da medida do perímetro; para isto, se utilizou fita crepe colada em torno do mesmo cujas extremidades foram ajustadas de acordo com o calibre do tronco; a fita foi removida e colada em papel para posterior medição com régua; esta medida foi tomada a aproximadamente $12,5 \mathrm{~cm}$ do colo da planta.

Para determinação da altura de planta foi utilizada uma mira falante (equipamento de uso em topografia). A estimativa da evapotranspiração de referência foi feita com os dados dos elementos meteorológicos obtidos na estação meteorológica automática do sistema do INMET; já para o cálculo da ETo se utilizou o modelo de Penman-Monteith, parametrizado por Allen et al. (1998).

\section{Construção, calibração e instalação dos sensores}

Utilizaram-se, na construção das sondas de dissipação térmica, 2 agulhas de aço inoxidável de tamanho 40 x 18 (uso veterinário), cortadas no comprimento desejado (2,5 cm, correspondente ao raio médio dos caules dos cafeeiros avaliados).

Um fio de termopar tipo T com 0,011 mm de diâmetro e comprimento de $28 \mathrm{~cm}$ foi dividido ao meio e o condutor de constantan de $14 \mathrm{~cm}$ foi utilizado para confeccionar a resistência aquecedora do sensor (resistência aproximada cerca de 6 ohms); a etapa seguinte foi confeccionar o cabo que liga os sensores ao sistema de registro de dados e fonte de corrente, para a qual se utilizaram $50 \mathrm{~cm}$ de cabo emborrachado de 4 vias (4 x 0,14 $\mathrm{mm}^{2}$ ). Na capa do isolador de $8 \mathrm{~cm}$ foi feito um furo central de aproximadamente $2 \mathrm{~mm}$ de diâmetro inserindo-se, neste furo, os 4 condutores expostos do cabo desencapado fazendo-se sair 3 condutores por uma das extremidades da capa isoladora e o quarto condutor sair na extremidade oposta; em seguida, os termopares foram ligados em série, unidos pelo condutor de constantan ao centro, restando duas extremidades em cobre, uma para ser ligada em um dos condutores da extremidade que contém 3 fios e a outra no condutor da extremidade oposta da capa (isolador).

Um fio de constantan de $14 \mathrm{~cm}$, reservado anteriormente, foi enrolado com o auxílio de lupa, em torno do termopar (Figura 1A) ligado do lado do circuito que continha os 3 condutores e se ligaram as suas extremidades aos 2 con-

A.

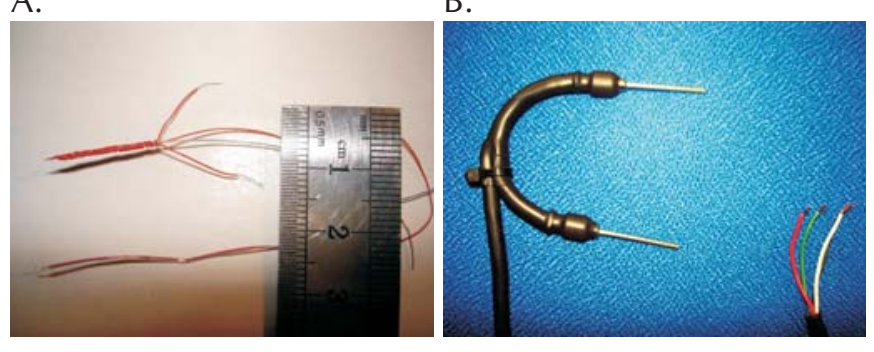

Figura 1. Ligação dos termopares com a resistência (A), sensor de dissipação térmica (B) dutores restantes; referido fio de constantan enrolado em torno do termopar servia como resistência da sonda dissipadora de calor. A Figura 1B apresenta o sensor já construído.

Construiu-se um circuito regulador de corrente para cada sensor de dissipação com o objetivo de manter a corrente e a potência dissipada constantes, mesmo com a variação da tensão entre 3 e $40 \mathrm{~V}$.

Antes da instalação no campo os sensores foram calibrados no laboratório, inseridos em meio isotérmico (isopor), mantidos na mesma altura do solo e ligados ao sistema de aquisição de dados para registrar as leituras; verificou-se a variabilidade entre os sensores e se realizaram os ajustes necessários para uniformização da potência dissipada em 0,2 W.

O sensor montado para este experimento sofreu algumas modificações daquele proposto por Granier (1985) uma vez que todo o conjunto (termopar + resistência) está inserido no interior da agulha; com isto, o sensor se tornou mais compacto, mais resistente ao manuseio de inserção e/ou remoção na planta, sem causar danos aos elementos do circuito, à exposição às variações climáticas e à resistência dos tecidos vasculares da planta, possibilitando a reutilização dos sensores em outros experimentos.

\section{Montagem do experimento}

Para inserir cada sensor no tronco, o caule da planta foi perfurado até o centro, no sentido transversal ao tronco, a $10 \mathrm{~cm}$ do solo, e o segundo furo a $5 \mathrm{~cm}$ acima do primeiro; introduziu-se, em cada furo, um tubo de latão de 2,5 mm de diâmetro e $30 \mathrm{~mm}$ de comprimento; este tubo servia para facilitar a inserção dos sensores e a troca de calor entre o sensor e o caule da planta.

Realizou-se sorteio para definir a posição de inserção do sensor em cada planta, de acordo com os pontos cardeais. A região de instalação dos sensores foi isolada termicamente cobrindo-se com plástico-bolha, para evitar o efeito da incidência da radiação eletromagnética sobre as medidas, a infiltração de água e o ataque de insetos.

O experimento foi instalado no início da primavera, quando os cafeeiros apresentavam copa bem formada e folhagem intensa época em que o estádio fenológico se constituía de gemas florais entumecidas, ou seja, antes do lançamento dos botões florais. A área efetiva de fluxo de seiva foi adotada como a área de toda a seção reta do tronco.

Delgado-Rojas (2003) descreve que o valor de $\Delta$ Tmáx pode sofrer variações devido, possivelmente, às propriedades térmicas do xilema; portanto, este valor foi calculado a cada $24 \mathrm{~h}$ obtendo-se, assim, o fluxo de seiva equivalente a este período. Em escala temporal diária e em ausência de stress hídrico severo, considera-se que este valor equivale à transpiração, isto é, o fluxo de seiva integrado em 24 h correspondeu à transpiração máxima diária da planta (Granier, 1985).

O delineamento experimental utilizado foi o inteiramente casualizado constituído de quatro tratamentos e seis repetições, totalizando 24 parcelas ou plantas avaliadas; os tratamentos foram relacionados à posição de inserção dos sensores e direcionados para o Norte, Sul, Leste ou Oeste; os dados foram analisados por análise de variância, utilizando-se o programa 
SAS (2002); as médias entre os tratamentos foram comparadas pelo teste Tukey a 5\% de significância.

\section{Medidas de fluxo de seiva}

Fez-se a medida do fluxo de seiva pelo método de dissipação de calor, sistema que consiste na inserção perpendicular ao tronco de duas sondas distanciadas $5 \mathrm{~cm}$ entre si, na mesma linha vertical, ou seja, em direção ao eixo do tronco. A sonda superior era aquecida de forma constante, com fornecimento de potência elétrica de 0,2 Watts de dissipação de calor. A variação da diferença de temperatura entre a sonda aquecida (superior) e a não aquecida (inferior) em cada instante foi determinada pelo transporte convectivo de calor, através da seiva; desta forma, a máxima diferença entre as duas sondas em um período significava que o fluxo de seiva foi mínimo ou nulo, enquanto a mínima diferença significava uma taxa máxima de fluxo de seiva através dessa área de transporte (Granier, 1987).

As diferenças de temperatura dos sensores do experimento foram registradas em "datalogger" marca Campbell, modelo CR23X e um multiplexador de canal do mesmo fabricante, com amostragem de leituras a cada 30 s e médias armazenadas a cada 15 min. Na Figura 2 se observam as duas sondas que compõem o sensor de Granier.

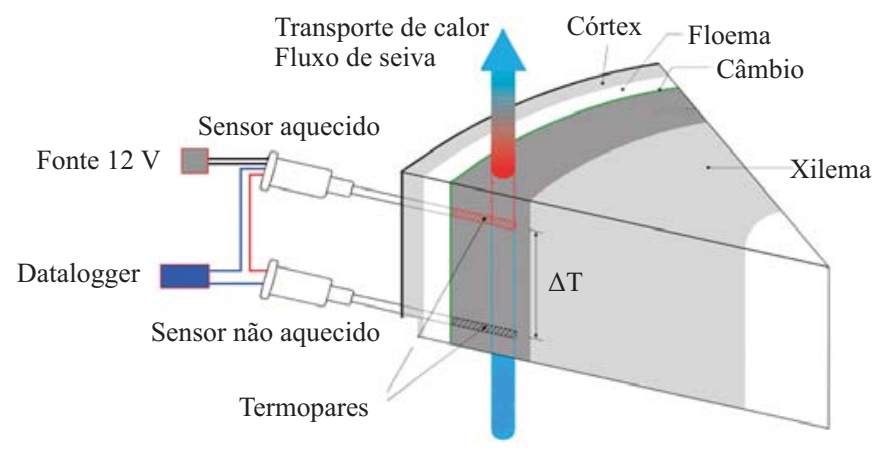

$\overline{\text { Figura 2. Esquema do sensor de Granier inserido perpendicularmente no tronco }}$

Granier (1985) propôs uma relação entre a densidade de fluxo de seiva u $\left(10^{-6} \mathrm{~m} \mathrm{~s}^{-1}\right)$ e um fator $\mathrm{k}$ característico de cada espécie vegetal. Trabalhando com três espécies lenhosas (Pseudotsuga menziesii, Pinus nigra e Quercus pedunculata) o autor encontrou a seguinte relação:

$$
\mathrm{k}=(\Delta \mathrm{Tm}-\Delta \mathrm{T}) / \Delta \mathrm{T}=0,0206^{*} \mathrm{u}^{0,8124} \quad \mathrm{R}^{2}=0,96
$$

sendo, $\Delta \operatorname{Tm}\left({ }^{\circ} \mathrm{C}\right)$ a diferença máxima de temperatura entre os dois pontos de medida que, normalmente, acontece durante a madrugada, e $\Delta \mathrm{T}\left({ }^{\circ} \mathrm{C}\right)$ a diferença de temperatura real; esta relação é transformada na Eq. 3, para se ter o fluxo de seiva $\mathrm{F}\left(\mathrm{m}^{3} \mathrm{~s}^{-1}\right)$ em qualquer espécie lenhosa, conforme recomendação do introdutor do método:

$$
\mathrm{F}=118,99 * 10^{-6} * \mathrm{~K}^{1,231} * \mathrm{SA}
$$

sendo: SA a área do lenho condutor da seiva bruta, dada em $\mathrm{m}^{2}$, normalmente considerada a área ocupada pelo xilema e k é calculado através da Eq. 2, a partir das medidas térmicas registradas através do sensor.

De início, as modificações realizadas nos sensores forneceram dados de diferenças de temperatura entre os sensores, superiores aos observados em outros trabalhos (Marin, 2003; Paço, 2003; Karasawa, 2006), inclusive em relação ao estudo de Granier (1985), motivo pelo qual foi necessário realizar uma calibração para obtenção de uma nova equação que correspondesse a valores equivalentes às leituras obtidas de fluxo de seiva no cafeeiro, nas condições estudadas.

\section{Calibração da equação de Granier (1985)}

Para sua calibração se construiu uma câmara de calibração de fluxo de seiva (Figura 3), constituída de uma bomba de compressão de ar, utilizada por manter a pressão constante, além de um cilindro reservatório de água, uma câmara de pressão feita em aço inox com uma das extremidades em forma de cone invertido, ou seja, voltado para dentro do cilindro; este cone é revestido com neoprene, duas hastes de rosca para facilitar fixação do tronco à câmara de calibração e uma célula de carga para quantificar o volume da água que passa pelo tronco (peso da água, considerando-se densidade igual a 1). Este sistema hidráulico foi construído conforme descrito por Fernandez et al. (2001) e Delgado-Rojas et al. (2006).

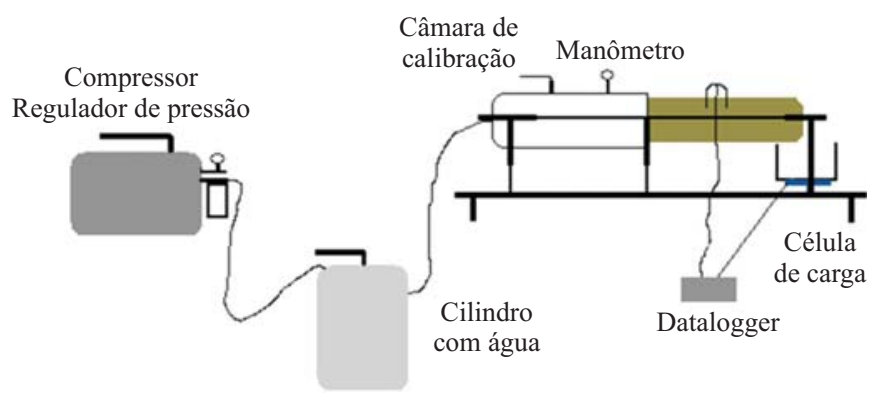

Figura 3. Representação esquemática da câmara de calibração de fluxo de seiva para simulação do fluxo de seiva

Uma secção do tronco de cafeeiro de cerca de $30 \mathrm{~cm}$ foi usada e inserida na bomba de compressão, que forçava a água do reservatório a passar pela secção do tronco. Um reservatório coletor montado sobre uma célula de carga (precisão de $0,01 \mathrm{~g}$ ) coletava a água na outra extremidade do tronco. As pressões aplicadas foram de 10, 50, 75, 100, 125 e $150 \mathrm{kPa}$, semelhantes às utilizadas por Braun \& Schmid (1999).

No procedimento de calibração foi inserido, no tronco, um par do sensor de Granier, com a sonda aquecida a montante da sonda de referência (não aquecida), espaçadas $5 \mathrm{~cm}$ entre si, para medir a diferença de temperatura entre as sondas que variou com a taxa do fluxo forçado de água. Para se obter a temperatura máxima entre os sensores, isto é, quando o fluxo era zero, a bomba de compressão de ar era desligada. Tanto as leituras da diferença de temperatura entre as sondas do sensor de fluxo de seiva quanto os volumes de água coletados no reservatório para cada pressão aplicada, eram registrados no sistema de aquisição de dados ou "datalogger" da Campbell Scientific, modelo 
CR10X, com amostragem de leituras a cada segundo e médias armazenadas a cada minuto.

\section{RESULTADOS E DISCUSSÃO}

\section{Caracterização meteorológica no período experimental}

No período avaliado entre os meses de setembro de 2007 e janeiro de 2008, não houve variação intensa nas condições climáticas para a área de estudo. Como se nota na Figura 4, a oscilação observada dos parâmetros no mês de outubro com relação aos demais meses, é devida às características da região, haja vista que em outubro ocorrem dias de intensa nebulosidade, baixa insolação, baixa temperatura, alta umidade relativa, elementos típicos nessa região no início da primavera.

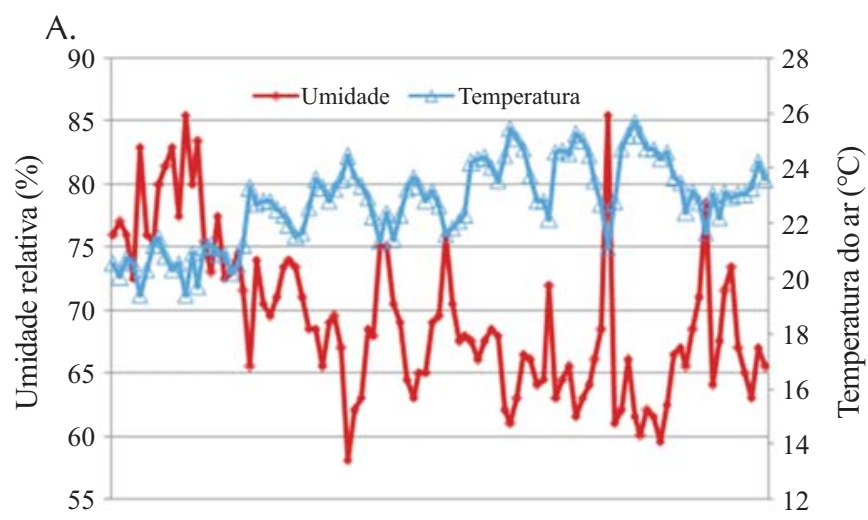

B.

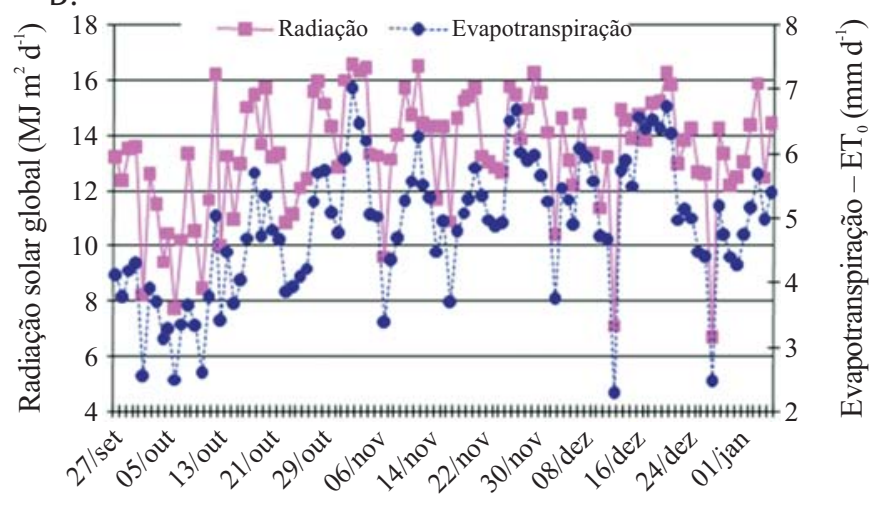

Figura 4. Variação diária da temperatura média do ar, da umidade relativa (A) e evapotranspiração de referência e radiação solar global (B) no período de 27/09/07 a 05/01/08, em Garanhuns, PE

\section{Biometria do cafeeiro}

Para caracterização das plantas avaliadas algumas variáveis fitométricas apresentadas na Tabela 1 foram mensuradas conforme descrito na metodologia; em relação à altura das plantas e do diâmetro do tronco, não variarem muito, em média 2,27 e 5,27 cm, respectivamente. Dentre as medidas realizadas a que apresentou maior amplitude foi a área foliar, com mínima de 3,67 $\mathrm{m}^{2}$ por planta e máxima de 12,25 $\mathrm{m}^{2}$.

\section{Equação da calibração}

Visando nova calibração, utilizaram-se os dados obtidos
Tabela 1. Altura da planta $(\mathrm{Al})$, perímetro do tronco $(\mathrm{P})$, diâmetro $(\phi)$ e área da seção reta do tronco (Ar), área foliar (AF) e ângulo de inserção (Al) dos sensores de fluxo de seiva em respectivas plantas (A) em 2007 - Garanhuns, PE

\begin{tabular}{rcccccc}
\hline $\mathbf{A}$ & $\mathbf{A l} \mathbf{( m )}$ & $\mathbf{P}(\mathbf{c m})$ & $\boldsymbol{\phi} \mathbf{( c m})$ & $\mathbf{A r}\left(\mathbf{c m}^{2}\right)$ & $\mathbf{A F}\left(\mathbf{m}^{2}\right)$ & Al \\
1 & 2,30 & 15,70 & 5,00 & 19,62 & 4,87 & Oeste \\
2 & 2,17 & 17,90 & 5,70 & 25,50 & 3,67 & Norte \\
3 & 2,40 & 17,10 & 5,44 & 23,27 & 8,82 & Norte \\
4 & 2,40 & 17,30 & 5,51 & 23,82 & 12,25 & Norte \\
5 & 2,40 & 14,90 & 4,74 & 17,67 & 10,44 & Leste \\
6 & 2,47 & 15,20 & 4,84 & 18,39 & 7,36 & Oeste \\
7 & 2,40 & 17,00 & 5,41 & 23,00 & 6,25 & Sul \\
8 & 2,50 & 17,30 & 5,51 & 23,82 & 10,18 & Sul \\
9 & 2,39 & 19,80 & 6,30 & 31,20 & 10,61 & Norte \\
10 & 2,42 & 18,60 & 5,92 & 27,53 & 10,41 & Oeste \\
11 & 2,36 & 17,10 & 5,44 & 23,27 & 5,49 & Oeste \\
12 & 2,08 & 15,70 & 5,00 & 19,62 & 5,74 & Sul \\
13 & 1,91 & 15,90 & 5,06 & 20,12 & 4,36 & Sul \\
14 & 2,20 & 15,90 & 5,06 & 20,12 & 5,46 & Leste \\
15 & 2,25 & 17,00 & 5,41 & 23,00 & 6,15 & Leste \\
16 & 2,26 & 16,40 & 5,22 & 21,40 & 4,87 & Norte \\
17 & 2,38 & 17,30 & 5,51 & 23,82 & 5,83 & Sul \\
18 & 2,00 & 14,90 & 4,74 & 17,67 & 5,70 & Leste \\
19 & 2,11 & 16,00 & 5,09 & 20,37 & 7,25 & Leste \\
20 & 2,18 & 14,30 & 4,55 & 16,27 & 3,76 & Oeste \\
21 & 2,33 & 15,80 & 5,03 & 19,87 & 6,75 & Oeste \\
22 & 2,35 & 17,10 & 5,44 & 23,27 & 9,30 & Leste \\
23 & 2,24 & 17,50 & 5,57 & 24,37 & 9,31 & Norte \\
24 & 2,03 & 16,20 & 5,16 & 20,88 & 5,22 & Sul \\
\hline & & & & & &
\end{tabular}

das variáveis térmicas $(\mathrm{K})$ do tronco do cafeeiro na câmara de calibração de fluxo de seiva, aplicada para a obtenção da densidade de fluxo (u); com isto se obteve a função que descreveu a curva de calibração dos sensores modificados, com novos coeficientes (Figura 5).

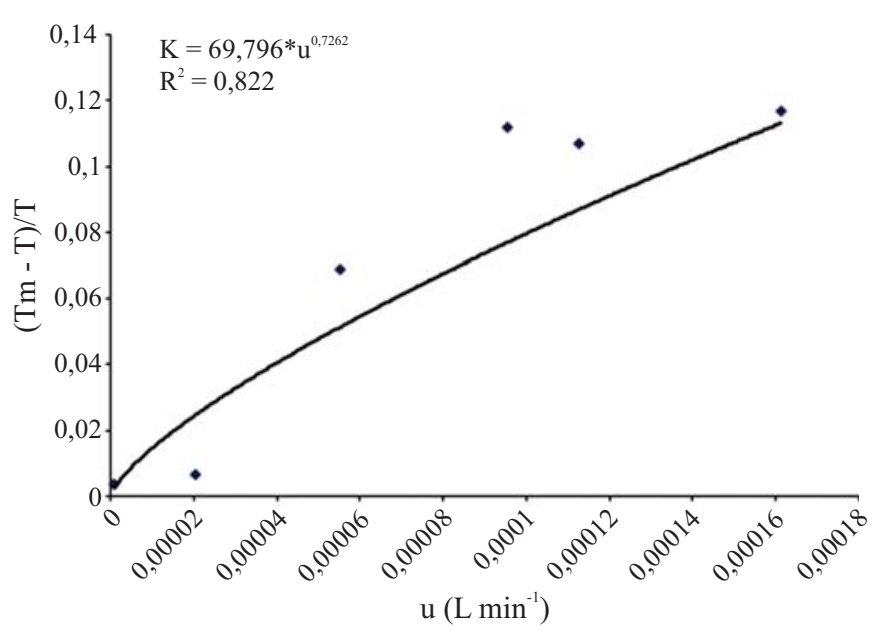

Figura 5. Relação entre u (densidade de fluxo de seiva) e $\mathrm{K}[(\mathrm{Tm}-\mathrm{T}) / \mathrm{T})]$ obtidos na câmara de calibração

A equação obtida a partir da regressão potencial dos dados, foi invertida para obtenção da densidade de fluxo de seiva $u$, em função da diferença de temperatura entre os 
sensores $k$, como recomendado por Granier (1985), resultando na Eq. 4.

$$
\mathrm{F}=0,00312951 * \mathrm{~K}^{1,3583} * \mathrm{SA}
$$

Com a equação obtida foi possível obter os valores de transpiração do cafeeiro para as condições de estudo e fazer comparações com os elementos meteorológicos a fim de identificar aqueles que mais afetam o consumo hídrico das plantas.

Paço (2003) relaciona o estabelecimento da relação $\mathrm{u}=118,99 * 10^{-6 *} \mathrm{k}^{1,} 231$ em Pseudotsuga menziesii, pinheiro (Pinus nigra), carvalho (Quercus pedunculata), macieira (Malus domestica) e castanheiro (Castanea sativa). Esta calibração também foi confirmada posteriormente em três espécies arbóreas tropicais (Eucalyptus deglupta, Anacardium excelsum e Bursera simaruba) por Clearwater et al. (1999) e Braun \& Schmid (1999) em videira. Cabibel \& Do (1991) se referem a uma calibração muito próxima desta, realizada em macieira, carvalho, castanheiro e em uma fibra sintética, obtendo-se:

$$
\mathrm{u}=136,83 * \mathrm{~K}^{1,2997}
$$

\section{Avaliação do método de Granier (1985)}

$\mathrm{O}$ equipamento instalado no campo registrava a diferença de temperaturas entre as duas sondas dos sensores. Na Figura 6A se verifica que, a medida em que amanhece, o fluxo de seiva aumenta e a diferença de temperatura diminui, isto é, a relação entre a temperatura e o fluxo é inversa, pois o fluxo promove o resfriamento da sonda aquecida diminuindo a variação de temperatura entre as sondas. Pode-se observar que a diferença de temperatura na variação da temperatura ao longo do dia, foi de $2,4^{\circ} \mathrm{C}$; esta variação registrada mostra que o sensor apresenta alto coeficiente de resposta em relação às diferenças de temperatura provocadas pelas mudanças na taxa de transpiração ocorridas durante o dia. Segundo Angelocci (2002), em condição hídrica normal da planta esta variação do fluxo acompanha normalmente a demanda atmosférica do meio ambiente, em função da radiação solar, temperatura, vento, umidade do ar etc.

Marin (2003) trabalhando com a variedade de cafeeiro Mundo Novo Apuatã, com 5 anos de idade na região de Piracicaba, SP, e utilizando método de balanço de calor, obteve variação de temperatura entre extremidades de no máximo $12{ }^{\circ} \mathrm{C}$ e Karasawa (2006) avaliando a cultivar Obatã IAC 1669-20 com 3 anos, em Piracicaba e utilizando o método de Granier, obteve diferença de até $10{ }^{\circ} \mathrm{C}$ entre sensores. Maiores valores de diferença de temperatura entre as sondas, em média de $25,5^{\circ} \mathrm{C}$ conseguida neste estudo, são atribuídos principalmente às alterações construtivas propostas neste trabalho, conforme descritas anteriormente, em relação ao sensor original do método de Granier.

A partir das diferenças de temperatura entre as sondas dos sensores e a área efetiva de fluxo de seiva de cada planta aplicados na Eq. 4, adaptada de Granier (1985), foi possível fazer a estimativa do fluxo de seiva do cafeeiro. A Figura 6B
A.

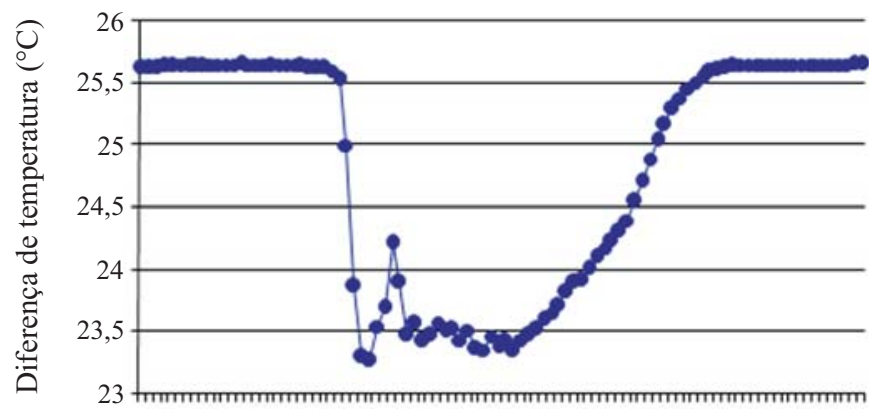

B.

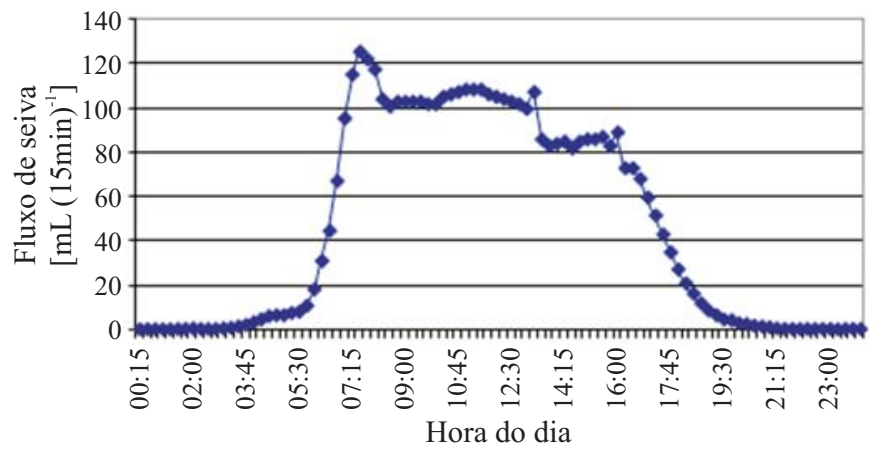

Figura 6. (A)Variação da diferença de temperatura entre sondas do sensor instalado em uma planta avaliada ao longo de um dia, com alta radiação $\left(26 \mathrm{MJ} \mathrm{m}^{2} \mathrm{~d}^{-1}\right)$. (B) Valores de densidade de fluxo de seiva de uma planta de café em $24 \mathrm{~h}$

representa a transpiração de uma planta com leituras a cada 15 min e área foliar de $3,67 \mathrm{~m}^{2}$ por planta.

Observa-se, nas primeiras horas do período matutino, que a curva tem uma progressão vertical muito rápida. Segundo Delgado-Rojas (2003) tal comportamento pode ser explicado levando-se em consideração que logo após o amanhecer, quando a planta começa a transpirar, o fluxo de seiva começa a aumentar, partindo de uma velocidade mínima (podendo ser nula) e como esta seiva é não aquecida (seiva fresca), ao atingir a parte inferior do segmento aquecido provoca queda drástica da temperatura naquele ponto, elevando rapidamente a diferença entre a temperatura deste ponto e a do extremo superior do segmento. Como a dissipação de calor convectivo é promovida pelo aumento subsequente do fluxo de seiva, o valor de temperatura da extremidade superior e inferior tende a diminuir voltando, portanto, à sua tendência normal; tal justificativa é atribuída ao método de balanço de calor mas esta variação da curva pelo método de Granier é semelhante à anterior, sendo o argumento compatível.

De acordo com Delgado-Rojas (2003) o uso do método de dissipação térmica resultou em valores diários de fluxo de seiva bastante concordantes com os dados de transpiração medidos pelos lisímetros, usados em plantas de citrus; ocorreu não só uma dispersão grande dos dados mas também tendência de superestimativa média de 35\% dos valores calculados pelo método de balanço de calor em relação ao método de dissipação térmica. Karasawa (2006) utilizando o fator de 1,3 sobre o fluxo obtido pelo método de Granier obteve a transpiração superestimada em média de $8 \%$ dos valores em relação à transpiração diária medida pelos lisímetros. 


\section{Avaliação quanto ao ângulo de inserção}

Nas avaliações quanto à variação da densidade do fluxo de seiva em função da posição de inserção do sensor, como se observa na Tabela 2, não houve diferença significativa no teste de média de Tukey a 5\% de significância. De acordo com o previsto, não se constatou maior concentração de fluxo de seiva em nenhum quadrante da planta para as condições do estudo, cuja variação na incidência luminosa foi mínima no período avaliado devido principalmente à proximidade com a linha do Equador (no experimento, as linhas de plantio estão na direção Norte-Sul). Granier (1987), trabalhando com pinheiro mostrou que em três orientações de inserção do sensor (ângulo de $120^{\circ}$ ) a $1 \mathrm{~m}$ do solo, as estimativas apresentaram discordância de $6 \%$ com relação à média, mas em condições climáticas da Europa.

Instalando quatro sensores, um em cada ponto cardeal e a duas alturas, a 1,5 e 8,5 m do solo em Pinus pinaster de 25 anos, Loustau et al. (1998) observaram que em dia ensolarado os sensores mais baixos apresentaram respostas diferenciadas, ao passo que nos sensores mais altos, não; esta resposta ocorreu em virtude, possivelmente, do sombreamento do caule pela copa na região das sondas mais altas, ao passo que a região das sondas mais baixas não foi atingida pela sombra da copa e, segundo eles, deu-se diferença entre as sondas do quadrante Leste e Oeste, porém no quadrante Norte e Sul os valores de fluxo de seiva foram semelhantes, no conjunto de sondas inferiores.

Tabela 2. Transpiração média $\left(\mathrm{L} \mathrm{d}^{-1}\right)$ em relação a cada ângulo da inserção do sensor de Granier nas plantas de café, em Garanhuns, PE

\begin{tabular}{cc}
\hline Tratamento & Transpiração $\left(\mathbf{L ~ d}^{-1}\right)$ \\
Norte & $5,38 \mathrm{a}$ \\
Sul & $5,83 \mathrm{a}$ \\
Leste & $5,00 \mathrm{a}$ \\
Oeste & $6,35 \mathrm{a}$ \\
\hline
\end{tabular}

Tem-se, na Figura 7 a média da transpiração obtida segundo os ângulos de inserção; nota-se, também, uma grande variação entre os fluxos (2 e $12 \mathrm{~L} \mathrm{~d}^{-1}$ ). Segundo Marin (2003), os valores de fluxo de seiva apresentaram grande variabilidade temporal entre as plantas, ao longo do experi-

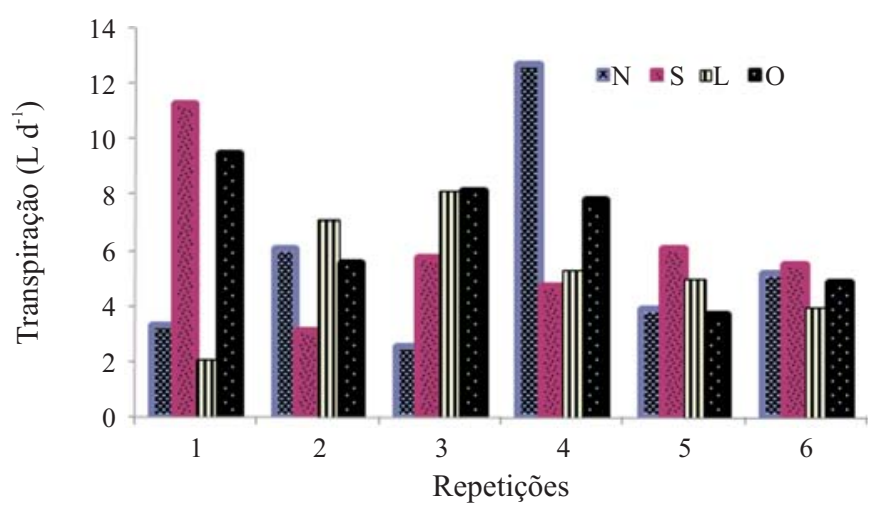

Figura 7. Variação da transpiração em cada ângulo de inserção nas 6 repetições durante o período de avaliação do cafeeiro, em Garanhuns, PE mento, com valores variando de $0,93 \mathrm{~L} \mathrm{~d}^{-1}$ com área foliar 6,0 $\mathrm{m}^{2}$ até $13,89 \mathrm{~L} \mathrm{~d}^{-1}$ com área foliar 13,9 m² e Karasawa (2006) obteve transpiração em torno de 2 e $4,5 \mathrm{~L} \mathrm{~d}^{-1}$ em plantas com área foliar entre 0,5 e 21,20 $\mathrm{m}^{2}$.

De maneira geral, os valores obtidos de transpiração se mantêm dentro dos intervalos obtidos pelos outros autores; salienta-se, no entanto, que esses trabalhos foram desenvolvidos em regiões distintas e se deve levar em consideração a fase fenológica em que essas avaliações foram realizadas.

\section{Avaliação quanto ao período de coleta}

Como não houve diferença em função dos tratamentos, o estudo foi dividido em 3 períodos, constituídos de 10 dias consecutivos, sendo: Período 1 - estabelecido entre os dias 09/10/07 a 18/10/07, denominado antecedente à floração; nesta fase, os botões florais estavam entumecidos; Período 2 - entre os dias 22/10/07 e 01/12/07 coincidindo com a própria floração, que teve seu pico registrado no dia 26/10/07 e Período 3 - entre os dias 27/12/07 e 05/01/08 denominado pósfloração; nesta fase se iniciou a formação dos frutos.

Conforme a escala de nota proposta por Pezzopane et al. (2003) o período 1 é classificado entre as notas 1, em que as gemas entumecem, e a nota 2, na qual os botões florais crescem devido à grande mobilização de água e nutrientes. O período 2 ficou entre a nota 3 , que se estende da abertura das flores até a nota 4, com posterior queda das pétalas enquanto o período 3 é equivalente à nota 5 , que se inicia após a fecundação e a formação dos frutos, fase esta denominada “chumbinho".

Camargo \& Camargo (2001) definem esses períodos em apenas uma fase, denominada florada, que se inicia com o aumento do potencial hídrico das gemas e se estende até a expansão dos frutos, com duração de quatro meses.

A transpiração média das plantas para o período 1 foi de $4,76 \mathrm{~L} \mathrm{~d}^{-1}$ e para os períodos seguintes foram respectivamente 6,55 e $7,98 \mathrm{~L} \mathrm{~d}^{-1}$, as quais não diferiram significativamente no teste Tukey a $5 \%$; contudo, destaca-se que para todas as fases avaliadas a demanda hídrica é muito intensa, a ponto de definir a produtividade.

A não diferenciação significativa da transpiração para os períodos observados pode ter ocorrido em razão do pequeno intervalo de avaliação (10 dias), no qual para as condições fisiológicas não há alteração representativa; portanto, se a comparação abrangesse toda a fase de floração comparada com a colheita ou o período de repouso (entre a colheita e a próxima floração), por exemplo, possivelmente esta diferença se acentuaria.

\section{Comparação da transpiração com os elementos meteorológicos}

A densidade de fluxo de seiva foi comparada com alguns elementos meteorológicos, como temperatura do ar, radiação solar e umidade relativa, obtidos dentro da área experimental, com leituras registradas a cada $15 \mathrm{~min}$.

A Figura 8 representa a regressão linear obtida com as médias de cada intervalo pré-estabelecidas de leituras do fluxo e do respectivo elemento. Como se pode observar, todos os elementos avaliados obtiveram boa relação com o fluxo de seiva, sendo os maiores a radiação solar com coeficiente 

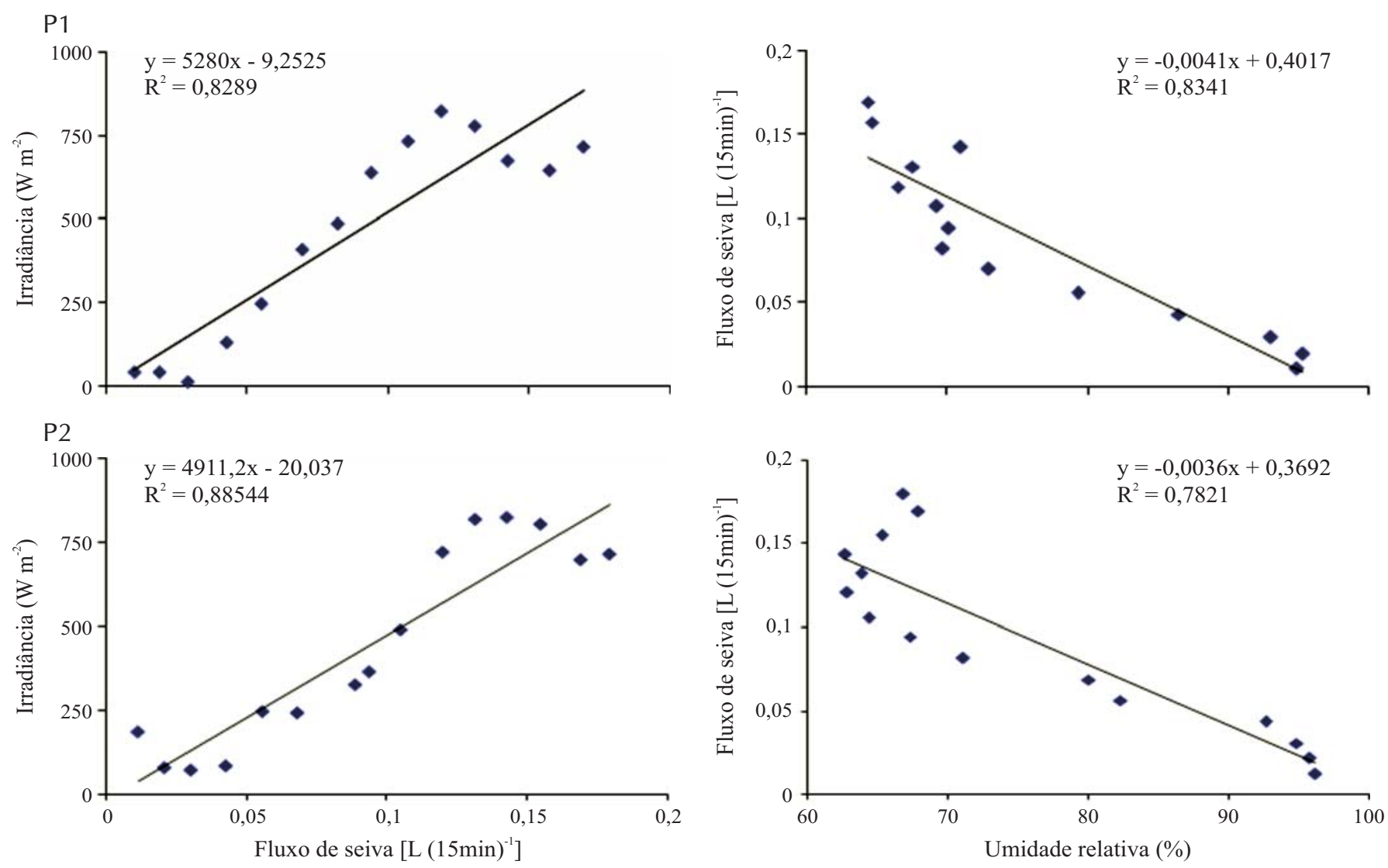

Figura 8. Relação entre fluxo de seiva com a irradiância e umidade relativa em P1 - antecedente à floração e P2 - pico da floração

de determinação em torno de 0,84 e umidade relativa em média 0,8 , nos períodos avaliados.

A evapotranspiração de referência foi relacionada com a transpiração para o período antecedente à floração e está representada na Figura 9. Nota-se concordância entre a transpiração e a evapotranspiração de referência, para a maioria das plantas.

Segundo Silva et al. (2003) a evapotranspiração de referência, radiação solar e déficit de pressão de vapor, apresentaram influência sobre a densidade de fluxo de seiva, em que as duas primeiras influenciaram, de forma linear, antes e após a colheita do café, tanto em parcela irrigada quanto na não irrigada. O padrão diário de densidade de fluxo de seiva se assemelhou ao da radiação solar.

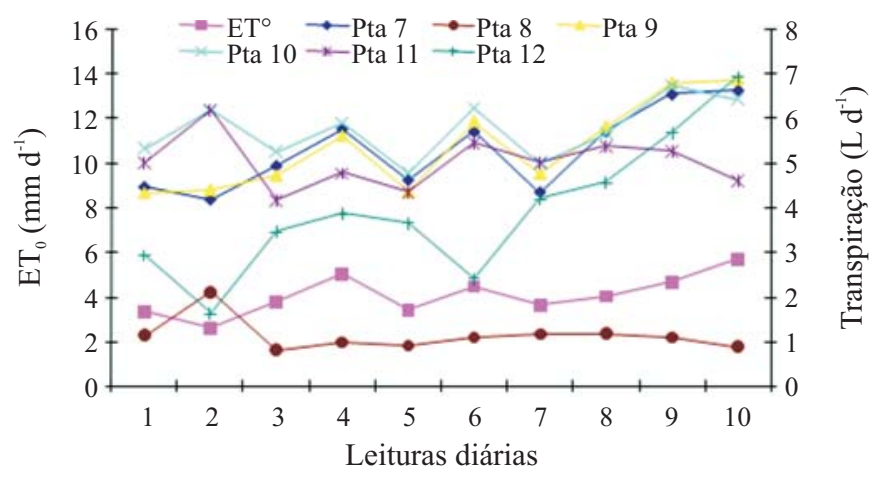

Figura 9. Variação da evapotranspiração de referência e da transpiração em 6 plantas no período 1 (09/10/07-18/10/07) em cafeeiro em Garanhuns, PE
A importância das condições meteorológicas durante o crescimento e o desenvolvimento da cultura do café é reconhecida por muitos pesquisadores desta atividade agrícola. Por outro lado, as características agroclimáticas das diversas regiões produtoras de café podem influenciar diferentemente a produtividade final da cultura (Evangelista et al., 2002).

\section{CONCLUSÕES}

1. Os resultados obtidos com o sensor de dissipação térmica modificado do método de Granier, permitiram estimar a transpiração dos cafeeiros nas condições do experimento.

2. A calibração da equação de Granier gerou novos coeficientes para o cafeeiro e foi possível utilizar esta equação com dados obtidos em condições de campo.

3. De acordo com o ângulo de inserção (Norte, Sul, Leste ou Oeste) não houve diferença significativa quanto à densidade de fluxo de seiva, implicando afirmar que, segundo as condições do estudo, o fluxo se distribui uniformemente no tronco.

4. As transpirações acompanharam a variação da evapotranspiração de referência em escala diária.

5. A densidade de fluxo de seiva foi influenciada pelos elementos meteorológicos medidos principalmente pela radiação solar e umidade relativa, nas condições experimentais. 


\section{LITERATURA CITADA}

Allen, R. G.; Pereira, L. S.; Raes, D.; Smith, M. Crop evapotranspiration: Guidelines for computing crop water requerements. Rome: FAO, 1998, 310p. Irrigation and Drainage Paper, 56

Angelocci, L. R. Água na planta e trocas gasosas/energéticas com a atmosfera. Piracicaba: 2002, 268p.

Braun, P.; Schmid, J. Sap flow measurements in grapevines (Vitis vinifera L.). I. Stem morphology and use of the heat balance method. Plant and Soil, v.215, p.39-45, 1999.

Cabibel, B.; Do, F. Mesures thermiques des flux de sève dans les troncs et les racines et fonctionnement hydrique des arbres: I - Analyse théorique des ereurs sur la mesure des flux et validation des mesures en présence de gradients thermiques extérieurs. Agronomie, v.11, p.669-678. 1991.

Camargo, A. P.; Camargo, M. B. P. Definições e esquematização das fases fenológicas do cafeeiro arábica nas condições tropicais do Brasil. Bragantia, v.60, n.1, p.65-80, 2001.

Clearwater, M. J.; Mainzer, F. C.; Andrade, J. L. Potential errors in measurement of no uniform sap flow using heat dissipation probes. Tree Physiology, v.19, p.681-687, 1999.

Delgado-Rojas, J. S. Avaliação do uso do fluxo de seiva e da variação de diâmetro do caule e de ramos na determinação das condições hídricas de citros, como base para o manejo de irrigação. Piracicaba: ESALQ/USP, 2003. 110p. Tese Doutorado

Delgado-Rojas, J. S.; Folegatti, M. V.; Angelocci, L. R. Calibração do método de sonda de dissipação térmica na determinação do fluxo de seiva em cafeeiro. In: Congresso Brasileiro de Engenharia Agrícola, 35, 2006, João Pessoa. Resumos... Jaboticabal: SBEA, 2006. CD-Rom.

Evangelista A. W. P.; Carvalho L. G.; Sediyama, G. C. Zoneamento climático associado ao potencial produtivo da cultura do café no Estado de Minas Gerais. Revista Brasileira de Engenharia Agrícola e Ambiental, v.6, n.3, p.445-452, 2002.

Fernandez, J. E.; Palomo, M. J.; Días-Espejo, A.; Clothier, B. E.; Green, S. R. Girón, I. F.; Moreno, F. Heat-pulse measurements of sap flow in olives for automating irrigation: test, root flow and diagnostics of water stress. Agricultural Water Management, v.51, p.99-123, 2001.

Granier, A. Une nouvelle méthode pour la mesure du flux de sève brute dans le tronc des arbres. Annales des Sciences Forestières, v.42, n.2, p.193-200, 1985.

Granier, A. Mensure du flux de sève brute dans le tronc du douglas par une nouvelle méthode thermique. Annales des Sciences Forestières, v.44, n.1, p.1-14, 1987.
Gutiérrez, M. V.; Meinzer, F. C. Energy balance and latent heat flux partitioning in coffee hedgerows at different stages of canopy development. Agricultural and Forest Meteorology, v.68, p.173-186, 1994.

Karasawa, S. Evapotranspiração de cafezal semi-adensado irrigado por gotejamento e sua relação com a evapotranspiração de referência. Piracicaba: ESALQ/USP, 2006. 97p. Tese Doutorado

Loustau, D.; Domec, J. C.; Bosc, A. Interpreting the variations in xylem sap flux density within the trunk of maritime pine ( $\mathrm{Pi}$ nus pinaster Ait.): Application of a model for calculating water flows at tree and stand levels. Annales des Sciences Forestierès, v.55, p.29-40, 1998.

Marin, F. R. Evapotranspiração e transpiração máxima de cafezal adensado. Piracicaba: ESALQ/USP, 2003. 118p. Tese Doutorado

Marshall, D. C. Measurement of sap flow in conifers by heat transport. Plant Physiology, v.33, n.6, p.385-396, 1958.

Mota, F. S.; Agendes, M. O. O. Clima e agricultura no Brasil 1.ed. Porto Alegre: Sagra Editora, 1986. 151p.

Paço, M. T. A. Modelação da evapotranspiração em cobertos descontínuos programação da rega em pomar de pessegueiro. Lisboa: Instituto Superior de Agronomia, Universidade Técnica de Lisboa. 2003. 251p. Tese Doutorado

Pezzopane, J. R. M.; Pedro Júnior, M. J.; Thomaziello, R. A.; Camargo, M. B. P. Escala para avaliação de estádios fenológicos do cafeeiro arábica. Bragantia, v.62, n.3, p.499-505, 2003.

Righi, E. Z. Balanço de energia e evapotranspiração de cafezal adensado em crescimento sob irrigação localizada. Piracicaba: ESALQ/USP, 2004. 151p. Tese Doutorado

Sakuratani, T. A heat balance method for measuring water flux in the stem of intact plants. Journal of Agricultural Meteorology, v.37, p.9-17, 1981.

SAS - Statistical Analysis System.Getting started with the SAS learning edition. Cary: SAS Institute Inc. 2002. CD-Rom

Silva, M. G.; Sousa, E. F.; Salassier, B.; Gomes, M. C. R.; Detmann, E.; Campostrini, E.; Oliveira, J. G.; Vieira, H. D.; Pinto, J. F.; Andrade, W. E. B. Densidade de fluxo de seiva do cafeeiro, antes e após a colheita, em parcela irrigada e não irrigada. In: Simpósio de Pesquisa dos Cafés do Brasil, 3, 2003, Porto Seguro. Resumos... Brasília: Embrapa Café, 2003. 238p. Viudes, A. M.; Alves Júnior, J.; Bonfim-Silva, E.; Silva, C. R.; Silva, T. J. A. Parâmetros fitométricos para estimativa da área foliar do café arábica. In: Simpósio Internacional de Iniciação Científica da USP, 12, 2004, Piracicaba. Resumos... Piracicaba: USP, 2004. CD-Rom 